\title{
Isolated Hepatic Perfusion with 200 mg Melphalan for Advanced Noncolorectal Liver Metastases
}

\author{
Liselot B. J. van Iersel, MD, ${ }^{1}$ Ellen J. Hoekman, ${ }^{1}$ Hans Gelderblom, MD, PhD, ${ }^{1}$ \\ Alexander L. Vahrmeijer, MD, PhD ${ }^{2}$ Els L. van Persijn van Meerten, MD ${ }^{3}$ Fred G. J. Tijl, ${ }^{4}$ \\ Henk H. Hartgrink, MD, PhD, ${ }^{2}$ Peter J. K. Kuppen, PhD, ${ }^{2}$ Johan W. R. Nortier, MD, PhD, ${ }^{1}$ \\ Rob A. E. M. Tollenaar, MD, PhD, ${ }^{2}$ and Cornelis J. H. van de Velde, MD, $\mathrm{PhD}^{2}$
}

\footnotetext{
${ }^{1}$ Department of Clinical Oncology, Leiden University Medical Center, Albinusdreef 2, 2333 ZA Leiden, The Netherlands

${ }^{2}$ Department of Surgery, Leiden University Medical Center, Albinusdreef 2, 2333 ZA Leiden, The Netherlands

${ }^{3}$ Department of Radiology, Leiden University Medical Center, Albinusdreef 2, 2333 ZA Leiden, The Netherlands

${ }^{4}$ Extra Corporal Circulation, Leiden University Medical Center, Albinusdreef 2, 2333 ZA Leiden, The Netherlands
}

The liver is one of the most common sites for metastatic disease and is involved in approximately $40 \%$ of adult patients with primary extrahepatic malignant disease who undergo an autopsy. The most

Published online May 10, 2008.

Address correspondence and reprint requests to: Liselot B. J. vanIersel, MD; E-mail: 1.b.j.van_iersel@lumc.nl

Published by Springer Science+Business Media, LLC @ 2008 The Society of Surgical Oncology, Inc. common origin of hepatic metastasis confined to the liver is colorectal cancer. Neuroendocrine tumors and uveal melanomas, although rare, are the second most common origin of metastases confined to the liver. ${ }^{1}$ Gastrointestinal neuroendocrine tumors are predominantly carcinoids $(55 \%)$, consisting mainly of midgut carcinoids (50-70\%) which have the greatest potential for metastasizing to the liver. ${ }^{2,3}$ Uveal melanoma is the most common primary intraocular tumor in 
adults, with an incidence of 5-7 per 1 million per year in the Western population. ${ }^{4} \mathrm{Up}$ to nearly $50 \%$ of patients will ultimately develop metastases, of which more than $60 \%$ is confined to the liver. ${ }^{5,6}$ Other primary tumors that may initially metastasize exclusively to the liver include gastrointestinal stromal tumors (GIST) and even more rarely renal cell carcinoma, Wilms' tumor, and breast cancer. Although liver metastases from primary tumors such as cancers of the lung, breast, stomach, and cutaneous melanoma may occur more frequently, dissemination usually occurs simultaneously to other visceral locations.

If the metastases are confined to the liver several locoregional treatment options can be considered, including partial hepatic resection, radiofrequency ablation (RFA), administration of chemotherapy by hepatic artery infusion (HAI), and isolated hepatic perfusion (IHP) with high-dose chemotherapy. Curative resection is possible in only a small fraction of patients due to the number, location or size of the metastases. ${ }^{7,8}$ RFA is mainly suitable for patients with a limited number of liver metastases that are not located near any large vascular structures and less than $5 \mathrm{~cm}$ in diameter. ${ }^{9-11}$ Compared to HAI, IHP offers the benefits of high local drug exposure with limited systemic toxicity. ${ }^{12}$ Various studies have been published on IHP for colorectal liver metastases, ${ }^{13-15}$ but only a few studies have been reported on IHP for liver metastases from other primary tumors. ${ }^{16-20}$

In this study we present our experience with 19 patients with a variety of primary tumors other than colorectal cancer, including uveal melanoma, high-grade sarcoma, and GIST, who underwent IHP at the Leiden University Medical Center.

\section{PATIENTS AND METHODS}

\section{Patient Eligibility}

Between May 1995 and May 2006, 19 patients with liver metastases of uveal melanoma (13), GIST (2), hepatocellular carcinoma (1), neuroendocrine carcinoma (2), and high-grade sarcoma (1) were treated with IHP with $200 \mathrm{mg}$ melphalan according to a study protocol approved by the local ethics committee. Using the same melphalan dose, during the accrual period, IHP was performed in 105 patients with colorectal cancer hepatic metastases (13, 15 and van Iersel, Annals of Oncology, in press 2008), indicating feasibility and our experience with this procedure. Informed consent was obtained from all patients. The tumour response of eight uveal melanoma patients has been previously reported. ${ }^{21}$ Eligibility criteria included a WHO performance status of 0 or 1 , leukocyte count $\geq 3.0 \times 10^{9} / \mathrm{L}$, platelet count $\geq 100 \times 10^{9} / \mathrm{L}$, maximum serum creatinine level $135 \mu \mathrm{mol} / \mathrm{L}$, maximum bilirubin level $17 \mu \mathrm{mol} / \mathrm{L}$, and minimum albumin level $40 \mathrm{~g} / \mathrm{L}$. Exclusion criteria were age over 70 years, life expectancy of less than 4 months, more than $60 \%$ hepatic replacement by tumor tissue as estimated from the preoperative abdominal computed tomography (CT) scan, coagulation disorders, and evidence of extrahepatic metastatic disease. All patients had a preoperative chest and abdominal computer tomography (CT), full blood count, liver function tests, and determination of lactate dehydrogenase, albumin and creatinine, and electrolytes.

\section{IHP Technique}

Briefly, the liver was mobilized from the diaphragm through a transverse abdominal incision. The common hepatic artery (8-Fr 77008 one-piece pediatric arterial cannula; Medtronic, Minneapolis, Minnesota, USA) and the portal vein (12-Fr perfex perfusion catheter CH12; B. Braun Medical, Oss, The Netherlands) were cannulated and connected to a heart-lung machine which consisted of two independent roller pumps (model 10-30-00; Cobe/Stöckert, Munich, Germany). For 14 patients both the hepatic artery and portal vein were used for inflow of melphalan in the isolated circuit, because this technique was used in our previously reported phase $\mathrm{I}^{15}$ and $\mathrm{II}^{13}$ study. Although there is no established benefit from drug delivery by using the portal vein during our IHP procedure oxygenated blood is perfused through the portal vein and this may possibly prevent hypoxiainduced damage to the liver. Moreover, by using our technique, the MTD of melphalan is much higher than reported by other groups who only used the hepatic artery for drug delivery. For five patients we used hepatic artery infusion at reduced flow as reported in a recent publication. ${ }^{22}$ The inferior vena cava (IVC) was cross-clamped above the hepatic veins and cannulated proximal of the renal veins (Polystan $36 \mathrm{Fr}$, straight, A/S, Värlöse, Denmark) to allow undisturbed blood flow from the hepatic veins through the IVC towards the heart-lung machine. To isolate the hepatic circuit, tourniquets were secured around the hepatic artery, portal vein, and IVC.

For the extracorporeal venovenous bypass, the right femoral vein (22-Fr cannula DIITF022L; Edwards Lifesciences, Irvine, California, USA) and the portal vein (17-Fr perfex perfusion catheter $\mathrm{CH} 17$; B. Braun) (proximal to the tourniquet) were cannu- 
lated and connected to the right axillary vein (18-Fr 7326 perfusion cannula; Lifestream International, The Woodlands, Texas, USA). The venovenous bypass was supported by a centrifugal pump (Medtronic BIO-Medicus, Eden Prairie, Minnesota, USA) and primed with $700 \mathrm{~mL} 0.9 \%$ saline. The perfusion medium consisted of intrahepatically trapped blood and $1250 \mathrm{~mL}$ Gelofusine ${ }^{\circledR}$ (Vifor Medical, Sempach, Switzerland) plus 2500 units heparin (Leo Pharma, Breda, The Netherlands) to yield a final volume of approximately 2 liters. Throughout the 1-h perfusion interval, the perfusate was kept at a temperature of $39.5^{\circ} \mathrm{C}$ by a heat exchanger and oxygenated using an oxygenator (Cobe VPCML; Cobe Cardiovascular, Arvada, Colorado, USA) except for the last three patients who were oxygenated using a different oxygenator (Dideco D901, SORIN group Italia, Mirandola, Italy). After perfusion, the liver was flushed for approximately $10 \mathrm{~min}$ with 3 liters Gelofusine ${ }^{\circledR}$. All cannula and clamps were removed, and the incisions were closed. To prevent possible melphalan induced cholecystitis, cholecystectomy was performed.

\section{Melphalan}

Melphalan 200mg (Alkeran ${ }^{\circledR}$, GlaxoSmithKline, Zeist, The Netherlands) was first dissolved in $40 \mathrm{~mL}$ Wellcome Diluent [a $60 / 40(\mathrm{v} / \mathrm{v})$ mixture of proylene glycol containing $5.2 \%(\mathrm{v} / \mathrm{v})$ ethanol and $0.068 \mathrm{~mol} / 1$ sodium citrate], which was subsequently diluted with $60 \mathrm{~mL}$ sterile saline. Melphalan was administered as a bolus in the isolated hepatic circuit ${ }^{13,15}$ and in the last five patients through 20-min infusion using an infusion pump (Pilote Anesthesie; Fresenius, Brezins, France) connected to the hepatic artery line of the isolated hepatic circuit. ${ }^{22}$

\section{Leakage Detection}

Leakage of perfusate into the systemic circuit was monitored by adding $10 \mathrm{MBq}{ }^{99 \mathrm{~m}} \mathrm{Tc}$-pertechnetate to the isolated circuit with subsequent measurement of the level of radioactivity in both the systemic and isolated circuit, as described previously. ${ }^{23,24}$ If no leakage was detected, melphalan was administered: If leakage was calculated to exceed $10 \%$ during the perfusion period, the procedure was stopped and the liver was flushed just before this level was reached.

\section{Postoperative Care}

All patients received a daily subcutaneous dose of $480 \mu \mathrm{g}$ granulocyte colony-stimulating factor
(G-CSF) (Filgrastim/Neupogen ${ }^{\circledR}$; Amgen, Breda, The Netherlands) starting the day after the operation until the nadir in leukocyte count was reached and the count had risen to more than $1.0 \times 10^{9} / \mathrm{L}$. Patients were monitored in the intensive care unit for at least 1 day after IHP. Liver and renal function tests and full blood counts were carried out daily in the first week and henceforth as indicated by their respective levels. Antibiotics in a combination of cefuroxim and metronidazol were given to all patients for 5 days after IHP.

\section{Toxicity}

Systemic and regional toxicity data were collected prospectively and graded retrospectively according to the National Cancer Institute Common Toxicity Criteria version 2.0. Hepatic toxicities were considered melphalan related if elevations in liver function persisted beyond 7 days after perfusion, as previously suggested. ${ }^{25}$

\section{Response Evaluation}

Objective tumor response measurements were obtained by follow-up CT scans of the liver and remaining abdomen at 3-month intervals after treatment and at 6-month intervals after 1 year. Additional imaging was performed if clinically indicated. All Ct scans were revised using RECIST criteria to determine response rates. For the response evaluation criteria in solid tumors (RECIST) criteria lesions were only considered measurable if $\geq 10 \mathrm{~mm}$, complete response was defined as disappearance of all known disease, partial response as a reduction in the sum of maximal diameters of $\geq 30 \%$, stable disease as a reduction of $<30 \%$ or an increase of $<20 \%$ and progressive disease as an increase of $\geq 20 \%$ or the appearance of new intra- or extrahepatic lesions. ${ }^{26}$ Disease-free survival was calculated from the date of IHP until the date of local and/or systemic recurrence or death from any cause.

\section{Statistical Analysis}

All data were analyzed with SPSS statistical software (version 14.0. for Windows, SPSS, Chicago, IL, USA). The analyses of time to progression and survival were carried out by the Kaplan-Meier method. If patients died before hepatic progression had occurred, date of death was taken as date of progression. 
TABLE 1. Patient and tumor characteristics

\begin{tabular}{ll}
\hline \multicolumn{1}{c}{ Characteristic } & \multicolumn{1}{c}{$\mathrm{n}(\%)$} \\
\hline $\begin{array}{l}\text { No. of patients } \\
\text { Sex }\end{array}$ & 19 \\
$\quad$ Male & $6(32)$ \\
Female & $13(68)$ \\
Primary tumor & 13 \\
$\quad$ Uveal melanoma & 2 \\
$\quad$ Neuroendocrine tumor & 2 \\
$\quad$ GIST & 1 \\
HCC & 1 \\
High-grade sarcoma & $51.4(29-69)$ \\
Median age in years (range) & \\
Liver metastases & $3(15.8)$ \\
$\quad$ Synchronous & $16(84.2)$ \\
Metachronous & $23.4(5-50)$ \\
Mean hepatic replacement, \% (range) & $12(1$ to $>100)$ \\
Median no. of metastases (range) & $2(0.7-13.7)$ \\
Median time of diagnoses of hepatic & \\
metastases to IHP & \\
\hline
\end{tabular}

\section{RESULTS}

\section{Patient and Treatment Characteristics}

Patient and tumor characteristics are listed in Table 1. A total of 19 patients with unresectable liver disease and no evidence of extrahepatic disease were considered eligible for IHP. Thirteen patients presented with uveal melanoma as primary tumor, two patients with a GIST, two patients with neuroendocrine carcinoma, one patient with hepatocellular carcinoma (HCC), and one patient with high-grade sarcoma. Sixteen patients presented with metachronous liver metastases. The mean number of liver metastases was 24 (range 1 to $>100$ ) with a mean estimated hepatic replacement of $23 \%$ (range 5$50 \%$ ). Mean time from diagnosis of liver metastases to IHP was 4.3 months (range 0.7-13.7 months). Five patients received chemotherapy prior to IHP.

All 19 patients underwent IHP, but in 1 patient the procedure failed due to failure to obtain sufficient isolation of the liver and this patient was excluded from further analyses. Treatment characteristics of the remaining 18 patients are similar to our previous experience with colorectal cancer patients and are listed in Table 2. ${ }^{13}$ Median operating time was 8 hours 7 min, with a median blood loss of 3.5 liters (range 1-8 liters). Median hospital stay was 11 days (range 7-25 days). Median follow-up was 74 months (range 4-137 months).

\section{Toxicity and Complications}

Ten patients experienced grade 3 or 4 toxicity of one or more liver enzymes 1 week after IHP, as
TABLE 2. Treatment parameters

\begin{tabular}{lc}
\hline \multicolumn{1}{c}{ Parameter } & Mean $\pm \mathrm{SD}$ \\
\hline Flow rate hepatic artery $(\mathrm{mL} / \mathrm{min})$ & $290.4 \pm 100$ \\
Flow rate portal vein $(\mathrm{mL} / \mathrm{min})$ & $230.8 \pm 97.3$ \\
Pressure hepatic artery $(\mathrm{mm} / \mathrm{Hg})$ & $118.1 \pm 24.6$ \\
Pressure portal vein $(\mathrm{mm} / \mathrm{Hg})$ & $36.5 \pm 9.3$ \\
Percentage leakage during perfusion & $2.6 \pm 4.9$ \\
Blood loss (L) & $3.9 \pm 2$ \\
Operative time (h) & $8.9 \pm 1.3$ \\
Hospital stay (days) & $12.7 \pm 4.8$ \\
\hline
\end{tabular}

shown in Table 3. This hepatoxicity was transient and only persisted in the four patients that developed veno-occlusive disease (VOD). Major complications occurred in five patients; as previously mentioned, four patients developed signs of VOD and one other patient experienced a lung embolism. Neutropenia was rare and no neutropenic infections occurred. Given the low leakage rate G-CSF, which was common practice since early development of this procedure in phase I, is deemed unnecessary in future patients. All patients left the hospital within 4 weeks.

\section{Tumor Response, and Progression-Free and Overall Survival}

The patients with uveal melanoma and the patients with liver metastases from other primary tumors were analyzed separately. The details on tumor responses, progression-free survival and overall survival details of the six patients with primary tumors other than uveal melanoma are given in Table 4. The high-grade sarcoma patient had a complete response for 27.1 months while one neuroendocrine tumor patient had a partial response for 33.4 months and was still alive at the end of follow-up.

Of the 12 uveal melanoma patients, $4(33 \%)$ patients had a partial hepatic response, $6(50 \%)$ patients had prolonged stable hepatic disease, and $2(17 \%)$ patients were immediately progressive. Progressive disease occurred in all patients during follow-up. Six $(50 \%)$ patients had hepatic progression, three $(25 \%)$ had extrahepatic progression, and three $(25 \%)$ were both hepatic and extrahepatic progressive. Progression-free and overall survival curves for uveal melanoma patients are shown in Fig. 1. The median time to hepatic progression was 8.2 months (range 1.717.1 months), while median time to overall progression after IHP was 6.6 months (range 1.717.1 months). All but one patient died during followup. The median overall survival after IHP was 10 months (range 4.8-47.6 months), with median 
TABLE 3. Toxicity according to National Cancer Institute Common Toxicity Criteria version $2.0(n=18)$

\begin{tabular}{|c|c|c|c|c|c|}
\hline & Grade 0 & Grade 1 & Grade 2 & Grade 3 & Grade 4 \\
\hline Leukocyte nadir & $63.2 \%(12)$ & $10.5 \%(2)$ & $5.3 \%(1)$ & $5.3 \%(1)$ & $10.5 \%(2)$ \\
\hline Bilirubin & $23.3 \%(5)$ & $21.1 \%(4)$ & $36.8 \%(7)$ & $0 \%(0)$ & $10.5 \%(2)$ \\
\hline Alkaline phosphatase & $5.3 \%(1)$ & $42.1 \%(8)$ & $21.1 \%(4)$ & $26.3 \%(5)$ & $0 \%(0)$ \\
\hline ALAT & $15.8 \%(3)$ & $26.3 \%(5)$ & $26.3 \%(5)$ & $21.1 \%(4)$ & $5.3 \%(1)$ \\
\hline ASAT & $5.3 \%(1)$ & $42.1 \%(8)$ & $21.1 \%(4)$ & $21.1 \%(4)$ & $5.3 \%(2)$ \\
\hline
\end{tabular}

Aspartate transaminase, ASAT; Alanine transaminase, ALAT

TABLE 4. Treatment results of IHP with $200 \mathrm{mg}$ melphalan in patients with isolated liver metastases of primary tumors other than uveal melanoma

\begin{tabular}{|c|c|c|c|c|c|c|}
\hline Patient & Primary tumor & $\begin{array}{l}\text { Hepatic } \\
\text { response }\end{array}$ & $\begin{array}{c}\text { Location } \\
\text { progression }\end{array}$ & $\begin{array}{l}\text { Time to progression } \\
\text { (months) }\end{array}$ & $\begin{array}{c}\text { Overall survival } \\
\text { after IHP (months) }\end{array}$ & $\begin{array}{c}\text { Survival after diagnosis } \\
\text { of liver metastases } \\
\text { (months) }\end{array}$ \\
\hline 1 & Neuroendocrine tumor & Stable disease & Extrahepatic & 5.9 & 8.9 & 18 \\
\hline 2 & Neuroendocrine tumor (carcinoid) & Partial remission & Extrahepatic & 33.4 & $89.4^{a}$ & $95.3^{a}$ \\
\hline 3 & GIST & Stable disease & Extrahepatic & 8 & 36.2 & 36.9 \\
\hline 4 & GIST & Stable disease & Hepatic & 13 & 22 & 23.8 \\
\hline 5 & $\mathrm{HCC}$ & Partial remission & Hepatic & 5.9 & 14.4 & 26.8 \\
\hline
\end{tabular}

${ }^{a}$ Patient was still alive at the end of follow-up. Data is censored at the end of follow-up.

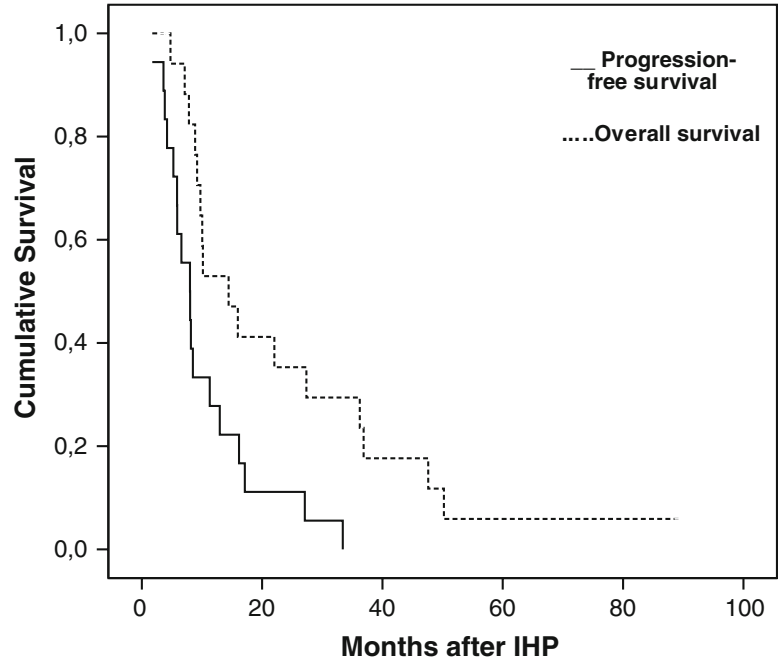

FIG. 1. Overall and progression-free survival curves for uveal melanoma patients. Of the 13 uveal melanoma patients, 12 patients were treated with IHP and included in the progression-free and overall survival analysis.

overall survival from diagnosis of liver metastasis of 12.2 months (range 8.7-49.6 months).

\section{DISCUSSION}

This study shows that IHP with $200 \mathrm{mg}$ melphalan shows activity in patients with liver metastases of primary tumors other than colorectal cancer. Transient grade 3 or 4 hepatotoxicity was observed in $56 \%$ of patients, similar to the results of previous studies. ${ }^{19,27}$ The incidence of VOD (4/18) was relatively high compared to the results in colorectal cancer patients. VOD is thought to result from cumulative exposure to chemotherapeutic agents, but only five patients in this study received chemotherapy prior to IHP and none of them developed VOD. ${ }^{28}$ The patients with VOD showed similar characteristics as compared to the patients without VOD, except for the fact that the incidence of VOD was higher $(2 / 5)$ in the patients treated with hepatic artery infusion at reduced flow, a technique that was recently abandoned by us because of limited response rates and hepatotoxicity. This leaves 3 VODs out of 13 patients treated with melphalan through hepatic artery and portal vein inflow, which is considered acceptable toxicity. Of note, $5 \%$ underwent a major laparotomy, but could not be perfused: this was due to extrahepatic disease that was not observed on CT scanning. In order to reduce the incidence of unexpected extrahepatic disease on laparotomy, optimal staging with positron emission tomography (PET) scanning is being introduced for future patients. Response rates, disease-free and overall survival remain difficult to interpret due to small numbers and should be evaluated in view of the lack of other treatment options in patients with the tumors that were included in this study.

For the treatment of metastatic uveal melanoma no standard systemic agent currently exists. Several studies have reported response rates of less than $10 \%$ 
to conventional systemic chemotherapy. ${ }^{29,30}$ Results with immunotherapy, as for example interferon- $\alpha$ and interleukin-2, are equally disappointing with no or only minor responses. ${ }^{31,32}$ Peters et al. reported the use of HAI with fotemustine, an alkylating agent, in 101 uveal melanoma patients with liver metastases. ${ }^{33}$ Fotemustine was infused in the hepatic artery for a 4week induction period followed by a maintenance treatment every 3 weeks until disease progression. A median of eight infusions per patient were delivered. Catheter related complications occurred in $23 \%$ of patients. The overall response rate was $36 \%$, with median overall survival of 15 months and 2-year survival rate of $29 \%$. Although the response rate of fotemustine infusion is similar to our results with IHP in uveal melanoma patients, the overall survival of 15 months seems superior to our observed 10 months. The difference could be explained by a difference in hepatic tumor load, but numbers estimating the tumor burden are not reported. The improved survival could also be attributed to the combination with debulking surgery in 38 patients undergoing HAI with fotemustine.

Alexander et al. reported the results of IHP with $1.5 \mathrm{mg} / \mathrm{kg}$ melphalan in 29 uveal melanoma patients. Hepatic response rate was $62 \%$ with progression-free survival of 8 months and overall survival of 12.1 months. In our patients the response rate was less, only $33 \%$, but $50 \%$ of patients did show stable disease with median time to progression of 6.6 months and overall survival of 10 months, similar to the results of Alexander et al. Although these results may seem disappointing as compared to IHP in other primary tumors, there is a survival benefit compared to a median survival of 2 months in uveal melanoma patients with liver metastases without antitumor treatment. ${ }^{34}$ Moreover, currently we have no accepted alternative treatment options for uveal melanoma patients with unresectable isolated liver metastases.

Treatment of neuroendocrine liver metastases is aimed at improvement of the hormonal symptoms through reduction of tumor burden. Results of systemically administered agents have been disappointing in neuroendocrine cancer metastases with response rates around $6-40 \%$ for cytostatic drugs and $11 \%$ for interferon- $\alpha .{ }^{35-38}$ Symptomatic improvement can be achieved in up to $70 \%$ of patients with somatostatin analogs such as octreotide, but objective tumor response occurs in less than $10 \%$ and drug resistance can develop in 3-12 months. ${ }^{39-42}$ Recently attention has shifted to the development of radiolabeled somatostatin analogs. Valkema et al. reported the response after peptide receptor radionuclide therapy with [90YDOTA0, Tyr3] octreotide in 56 patients with advanced neuroendocrine tumors. ${ }^{43}$ Overall, $58 \%$ of patients experienced improvement of symptoms, the median progression free survival was 29 months with a median overall survival of nearly 37 months. Several studies have been reported on the use of RFA for neuroendocrine liver metastases. ${ }^{44-46}$ In the largest published study the laparoscopic ablation of 234 hepatic lesions in 34 patients is reported. ${ }^{47}$ Symptoms were relieved in $95 \%$ of the patients, with significant or complete symptom control in $80 \%$ of them for a mean duration of 10 months. New liver metastases developed in $28 \%$ of these patients, new extrahepatic disease in $25 \%$, and local liver recurrence in $13 \%$, at a mean follow-up of 1.6 years. Grover et al. reported an overall response rate of 50\% with IHP in 13 neuroendocrine tumors with a median progression free survival of 7 months. ${ }^{48}$ Although we treated only two patients with neuroendocrine tumors, one patient with a carcinoid showed a partial response for 33.4 months. In neuroendocrine carcinoid tumors caution should be taken to block hormone secretion, because systemic complications have been reported during RFA of carcinoids. ${ }^{49}$

Imatinib has become the standard first-line systemic treatment for advanced GIST. GISTs have characteristic gain-of-function mutations in the KIT oncogene that results in overexpression of the KIT-protein (CD117) ${ }^{50}$ Imatinib is a potent, specific KIT/PDGFR-small molecule tyrosine kinase inhibitor with a patient benefit rate (prolonged stable disease and response) of up to $90 \%$ and median progression-free survival of $2.5-3$ years. ${ }^{51,52}$ Secondline treatment with sunitinib, an oral multitargeted receptor tyrosine kinase inhibitor, can add a median of 8 months in about $60 \%$ of patients. ${ }^{53}$ Before the imatinib/sunitinib era no systemic treatment options existed for metastatic GIST. Hepatic arterial chemoembolization was one of the options for patients with hepatic metastasis derived from GIST resulting in a mean survival of 9.5-11.4 months. ${ }^{54,55}$ The addition of RFA to transcatheter arterial chemoembolization could increase survival to up to 25 months. ${ }^{56}$ To our knowledge there have been no reports published on IHP for GIST. In our study two patients with GIST were included and showed stable disease with disease-free survival of 8 and 13 months, respectively, and overall survival of 36.2 and 22 months, respectively. Both patients were treated prior to the imatinib/sunitinib era. The aforementioned local treatment options, including IHP, can 
thus be considered in patients refractory to imatinib and sunitinib with progressive liver lesions without further extrahepatic progression.

In recent studies with IHP, melphalan with or without TNF- $\alpha$, has been the only chemotherapeutic agent used. Melphalan is an alkylating agent that is mainly used in the systemic treatment for multiple myeloma, isolated limb, lung, and liver perfusion. Little is known about the effectiveness of systemic melphalan treatment in the tumors described above. If IHP is considered as serious treatment option for patients with a variety of primary tumors other tumor-specific agents need to be studied to improve tumor response. Ideally, tumor-specific IHP agents should be developed. A wide range of agents is possible because, for example, IHP offers the additional advantage that, as long as agents are specific to the tissue of origin of the primary tumor, they do not have to differentiate between malignant and healthy tissue due to the local exposure in the liver.

In conclusion, IHP appears to be feasible in patients with liver metastases from a variety of primary tumors. To improve responses in IHP, the role of new agents tailored to specific tumor types needs to be assessed.

\section{OPEN ACCESS}

This article is distributed under the terms of the Creative Commons Attribution Noncommercial License which permits any noncommercial use, distribution, and reproduction in any medium, provided the original author(s) and source are credited.

\section{REFERENCES}

1. Sutcliffe R, Maguire D, Ramage J, et al. Management of neuroendocrine liver metastases. Am J Surg 2004; 187:39-46.

2. Shebani KO, Souba WW, Finkelstein DM, et al. Prognosis and survival in patients with gastrointestinal tract carcinoid tumors. Ann Surg 1999; 229:815-21.

3. Moertel CG, Sauer WG, Dockerty MB, et al. Life history of the carcinoid tumor of the small intestine. Cancer 1961; 14:901-12.

4. Egan KM, Seddon JM, Glynn RJ, et al. Epidemiologic aspects of uveal melanoma. Surv Ophthalmol 1988; 32:239-51.

5. Rajpal S, Moore R, Karakousis CP. Survival in metastatic ocular melanoma. Cancer 1983; 52:334-6.

6. Assessment of metastatic disease status at death in 435 patients with large choroidal melanoma in the Collaborative Ocular Melanoma Study (COMS): COMS report no. 15. Arch Ophthalmol 2001; 119:670-6.

7. Ihse I, Persson B, Tibblin S. Neuroendocrine metastases of the liver. World J Surg 1995; 19:76-82.

8. Scheele J, Stang R, Altendorf-Hofmann A, et al. Resection of colorectal liver metastases. World J Surg 1995; 19:59-71.
9. Solbiati L, Livraghi T, Goldberg SN, et al. Percutaneous radiofrequency ablation of hepatic metastases from colorectal cancer: long-term results in 117 patients. Radiology 2001; 221: 159-66.

10. Berber E, Pelley R, Siperstein AE. Predictors of survival after radiofrequency thermal ablation of colorectal cancer metastases to the liver: a prospective study. J Clin Oncol 2005; 23: 1358-64.

11. Sutherland LM, Williams JA, Padbury RT, et al. Radiofrequency ablation of liver tumors: a systematic review. Arch Surg 2006; 141:181-90.

12. Marinelli A, van de Velde CJ, Kuppen PJ, et al. A comparative study of isolated liver perfusion versus hepatic artery infusion with mitomycin C in rats. Br J Cancer 1990; 62:891-6.

13. Rothbarth J, Pijl ME, Vahrmeijer AL, et al. Isolated hepatic perfusion with high-dose melphalan for the treatment of colorectal metastasis confined to the liver. Br J Surg 2003; 90:1391-7.

14. Alexander HR, Libutti SK, Bartlett DL, et al. A phase I-II study of isolated hepatic perfusion using melphalan with or without tumor necrosis factor for patients with ocular melanoma metastatic to liver. Clin Cancer Res 2000; 6:3062-70.

15. Vahrmeijer AL, van Dierendonck JH, Keizer HJ, et al. Increased local cytostatic drug exposure by isolated hepatic perfusion: a phase I clinical and pharmacologic evaluation of treatment with high dose melphalan in patients with colorectal cancer confined to the liver. Br J Cancer 2000; 82:1539-46.

16. Noter SL, Rothbarth J, Pijl ME, et al. Isolated hepatic perfusion with high-dose melphalan for the treatment of uveal melanoma metastases confined to the liver. Melanoma Res 2004; 14:67-72.

17. Grover AC, Libutti SK, Pingpank JF, et al. Isolated hepatic perfusion for the treatment of patients with advanced liver metastases from pancreatic and gastrointestinal neuroendocrine neoplasms. Surgery 2004; 136:1176-82.

18. Feldman ED, Wu PC, Beresneva T, et al. Treatment of patients with unresectable primary hepatic malignancies using hyperthermic isolated hepatic perfusion. J Gastrointest Surg 2004; $8: 200-7$.

19. Alexander HR Jr, Libutti SK, Pingpank JF, et al. Hyperthermic isolated hepatic perfusion using melphalan for patients with ocular melanoma metastatic to liver. Clin Cancer Res 2003; 9:6343-9.

20. Alexander HR, Libutti SK, Bartlett DL, et al. A phase I-II study of isolated hepatic perfusion using melphalan with or without tumor necrosis factor for patients with ocular melanoma metastatic to liver. Clin Cancer Res 2000; 6:3062-70.

21. Noter SL, Rothbarth J, Pijl ME, et al. Isolated hepatic perfusion with high-dose melphalan for the treatment of uveal melanoma metastases confined to the liver. Melanoma Res 2004; 14:67-72.

22. van Iersel LB, Verlaan MR, Vahrmeijer AL, et al. Hepatic artery infusion of high-dose melphalan at reduced flow during isolated hepatic perfusion for the treatment of colorectal metastases confined to the liver: a clinical and pharmacologic evaluation. Eur J Surg Oncol 2007; 33:874-81.

23. Marinelli A, de Brauw LM, Beerman H, et al. Isolated liver perfusion with mitomycin $\mathrm{C}$ in the treatment of colorectal cancer metastases confined to the liver. Jpn J Clin Oncol 1996; 26:341-50

24. Runia RD, de Brauw LM, Kothuis BJ, et al. Continuous measurement of leakage during isolated liver perfusion with a radiotracer. Int J Rad Appl Instrum B 1987; 14:113-8.

25. Alexander HR Jr, Bartlett DL, Libutti SK, et al. Isolated hepatic perfusion with tumor necrosis factor and melphalan for unresectable cancers confined to the liver. J Clin Oncol 1998; 16:1479-89.

26. Therasse P, Arbuck SG, Eisenhauer EA, et al. New guidelines to evaluate the response to treatment in solid tumors. European Organization for Research and Treatment of 
Cancer, National Cancer Institute of the United States, National Cancer Institute of Canada. J Natl Cancer Inst 2000; 92:205-16.

27. Grover AC, Libutti SK, Pingpank JF, et al. Isolated hepatic perfusion for the treatment of patients with advanced liver metastases from pancreatic and gastrointestinal neuroendocrine neoplasms. Surgery 2004; 136:1176-82.

28. King PD, Perry MC. Hepatotoxicity of chemotherapeutic and oncologic agents. Gastroenterol Clin North Am 1995; 24: 969-90.

29. Bedikian AY, Legha SS, Mavligit G, et al. Treatment of uveal melanoma metastatic to the liver: a review of the M. D. Anderson Cancer Center experience and prognostic factors. Cancer 1995; 76:1665-70.

30. Flaherty LE, Unger JM, Liu PY, et al. Metastatic melanoma from intraocular primary tumors: the Southwest Oncology Group experience in phase II advanced melanoma clinical trials. Am J Clin Oncol 1998; 21:568-72.

31. Agarwala SS, Hellstrand K, Gehlsen K, et al. Immunotherapy with histamine and interleukin 2 in malignant melanoma with liver metastasis. Cancer Immunol Immunother 2004; 53:840-1.

32. Bedikian AY. Metastatic uveal melanoma therapy: current options. Int Ophthalmol Clin 2006; 46:151-66.

33. Peters S, Voelter V, Zografos L, et al. Intra-arterial hepatic fotemustine for the treatment of liver metastases from uveal melanoma: experience in 101 patients. Ann Oncol 2006; 17: 578-83.

34. Gragoudas ES, Egan KM, Seddon JM, et al. Survival of patients with metastases from uveal melanoma. Ophthalmology 1991; 98:383-9.

35. Kulke MH, Wu B, Ryan DP, et al. A phase II trial of irinotecan and cisplatin in patients with metastatic neuroendocrine tumors. Dig Dis Sci 2006; 51:1033-8.

36. Moertel CG, Kvols LK, O' Connell MJ, et al. Treatment of neuroendocrine carcinomas with combined etoposide and cisplatin. Evidence of major therapeutic activity in the anaplastic variants of these neoplasms. Cancer 1991; 68:227-32.

37. Rivera E, Ajani JA. Doxorubicin, streptozocin, and 5-fluorouracil chemotherapy for patients with metastatic islet-cell carcinoma. Am J Clin Oncol 1998; 21:36-8.

38. Oberg K. Interferon in the management of neuroendocrine GEP-tumors: a review. Digestion 2000; 62(Suppl 1):92-7.

39. Kvols LK, Moertel CG, O'Connell MJ, et al. Treatment of the malignant carcinoid syndrome. Evaluation of a long-acting somatostatin analogue. $N$ Engl J Med 1986; 315:663-6.

40. Oberg K. Endocrine tumors of the gastrointestinal tract: systemic treatment. Anticancer Drugs 1994; 5:503-19.

41. Oberg K, Norheim I, Theodorsson E. Treatment of malignant midgut carcinoid tumours with a long-acting somatostatin analogue octreotide. Acta Oncol 1991; 30:503-7.

42. Vinik A, Moattari AR. Use of somatostatin analog in management of carcinoid syndrome. Dig Dis Sci 1989; 34(3 Sup$\mathrm{pl}): 14 \mathrm{~S}-27 \mathrm{~S}$.
43. Valkema R, Pauwels S, Kvols LK, et al. Survival and response after peptide receptor radionuclide therapy with [90YDOTA0,Tyr3]octreotide in patients with advanced gastroenteropancreatic neuroendocrine tumors. Semin Nucl Med 2006; 36:147-56.

44. Hellman P, Ladjevardi S, Skogseid B, et al. Radiofrequency tissue ablation using cooled tip for liver metastases of endocrine tumors. World J Surg 2002; 26:1052-6.

45. Henn AR, Levine EA, McNulty W, et al. Percutaneous radiofrequency ablation of hepatic metastases for symptomatic relief of neuroendocrine syndromes. AJR Am J Roentgenol 2003; 181:1005-10.

46. Wessels FJ, Schell SR. Radiofrequency ablation treatment of refractory carcinoid hepatic metastases. J Surg Res 2001; 95: $8-12$

47. Berber E, Flesher N, Siperstein AE. Laparoscopic radiofrequency ablation of neuroendocrine liver metastases. World $J$ Surg 2002; 26:985-90.

48. Grover AC, Libutti SK, Pingpank JF, et al. Isolated hepatic perfusion for the treatment of patients with advanced liver metastases from pancreatic and gastrointestinal neuroendocrine neoplasms. Surgery 2004; 136:1176-82.

49. Wettstein M, Vogt C, Cohnen M, et al. Serotonin release during percutaneous radiofrequency ablation in a patient with symptomatic liver metastases of a neuroendocrine tumor. Hepatogastroenterology 2004; 51:830-2.

50. Hirota S, Isozaki K, Moriyama Y, et al. Gain-of-function mutations of c-kit in human gastrointestinal stromal tumors. Science 1998; 279:577-80.

51. Demetri GD, von Mehren M, Blanke CD, et al. Efficacy and safety of imatinib mesylate in advanced gastrointestinal stromal tumors. $N$ Engl J Med 2002; 347:472-80.

52. van Oosterom AT, Judson I, Verweij J, et al. Safety and efficacy of imatinib (STI571) in metastatic gastrointestinal stromal tumours: a phase I study. Lancet 2001; 358:1421-3.

53. Demetri GD, van Oosterom AT, Garrett CR, et al. Efficacy and safety of sunitinib in patients with advanced gastrointestinal stromal tumour after failure of imatinib: a randomised controlled trial. Lancet 2006; 368:1329-38.

54. Patel SR, Benjamin RS. Management of peritoneal and hepatic metastases from gastrointestinal stromal tumors. Surg Oncol 2000; 9:67-70.

55. Tarazov PG. Transcatheter therapy of gastric cancer metastatic to the liver: preliminary results. J Gastroenterol 2000; 35:907-11

56. Bloomston M, Binitie O, Fraiji E, et al. Transcatheter arterial chemoembolization with or without radiofrequency ablation in the management of patients with advanced hepatic malignancy. Am Surg 2002; 68:827-31. 